\title{
Tuberous sclerosis complex and Wolff-Parkinson-White syndrome
}

\author{
F J K O’Callaghan, A C Clarke, H Joffe, B Keeton, R Martin, A Salmon, R D Thomas, \\ J P Osborne
}

\begin{abstract}
This report highlights the association between tuberous sclerosis and WolffParkinson-White syndrome. Ten patients with concurrent diagnoses of WolffParkinson-White syndrome and tuberous sclerosis were identified. Wolff-ParkinsonWhite syndrome presented early in life, nine cases being diagnosed in the first year. Eight of the 10 cases were male. In eight cases, the syndrome was associated with supraventricular tachycardias, and in nine with cardiac rhabdomyomata. One child died from cardiac failure secondary to obstruction of the left ventricular outflow tract by a rhabdomyoma. Five of nine survivors showed resolution of WolffParkinson-White syndrome on follow up. The accessory pathway was localised in nine patients from surface electrocardiograms: six children had left sided pathways and three had right sided pathways. (Arch Dis Child 1998;78:159-162)
\end{abstract}

Keywords: tuberous sclerosis; cardiac rhabdomyoma; Wolff-Parkinson-White syndrome; supraventricular tachycardia

Tuberous sclerosis complex is a dominantly inherited genetic disease. The condition shows genetic heterogeneity, with gene loci on chromosomes 9 and $16 .{ }^{12}$ Both genes have been identified. ${ }^{3}{ }^{4}$ Both are tumour suppressor genes, which explains why they apparently produce an identical clinical phenotype characterised by the formation of multiple hamartomas. ${ }^{5}$ Formerly recognised by the clinical triad of epilepsy, mental retardation, and facial angiofibromatosis, it is now appreciated that almost any organ in the body, with the exception of skeletal muscle, may be affected. ${ }^{6}$ The disease is estimated to have a birth incidence of one in 6000 and more than $70 \%$ of cases will be new mutations. ${ }^{7}$ Over half the affected individuals will be intellectually normal. ${ }^{8}$ The most common cardiac manifestation of the disease is the cardiac rhabdomyoma, which is thought to occur in at least $60 \%$ of children with tuberous sclerosis. The natural history of these tumours is that they regress with increasing age. They may cause no symptoms, but in a minority of cases there may be obstruction of blood flow within the heart. ${ }^{9}$ There have also been a few isolated reports of Wolff-Parkinson-White syndrome occurring in association with tuberous sclerosis (table 1).

Wolff-Parkinson-White syndrome results from the presence of an accessory atrioven- tricular conducting pathway. It can be diagnosed during sinus rhythm from an electrocardiogram (ECG): there is a shortened PR interval and the QRS complex is deformed and widened in its initial portion by a slow rising slurred deflection called a delta wave. The presence of the accessory pathway predisposes these individuals to an atrioventricular reentry tachycardia. A small proportion of individuals with Wolff-Parkinson-White syndrome will have underlying cardiac disease: ventricular septal defect, Ebstein's malformation of the tricuspid valve, hypertrophic cardiomyopathy, and endocardial cushion defects are the most common associations. It occurs in $0.15 \%$ of the general population and in $0.5 \%$ of children with cardiac disease. ${ }^{24}$ However, the intermittent nature of the abnormalities makes it difficult to estimate the prevalence precisely. Patients usually present either in the first year of life or in late childhood or early adult life.

The association of Wolff-Parkinson-White syndrome with tuberous sclerosis is not well known. There have been isolated case reports and references to the association in papers on cardiac rhabdomyomata and tuberous sclerosis (table 1). We now report a series of 10 patients with tuberous sclerosis and Wolff-ParkinsonWhite syndrome and compare the natural history of this syndrome in tuberous sclerosis and in other situations.

\section{Methods}

We sought cases of tuberous sclerosis with a concurrent diagnosis of Wolff-ParkinsonWhite syndrome, and examined their medical histories to ensure that the diagnosis of tuberous sclerosis met established diagnostic criteria. ${ }^{25}$ All patients had an ECG record during sinus rhythm that showed a shortened PR interval and a widened QRS complex with a delta wave. We reviewed all available ECGs to confirm the diagnosis and to monitor the natural history of the electrical abnormalities. The anatomical position of the accessory pathways was identified from surface ECGs, using the algorithm described by Fitzpatrick et al. ${ }^{26}$

\section{Results}

We identified 10 children with a diagnosis of tuberous sclerosis and Wolff-Parkinson-White syndrome (table 2), five through a prevalence study in the Wessex region, two during a previous national survey of cardiac rhabdomyomata, one through a family genetic linkage study, and two by personal referral. There were eight males and two females. In six of the 10 children Wolff-Parkinson-White syndrome was diag- 
Table 1 Published reports of cases of tuberous sclerosis and Wolff-Parkinson-White syndrome

\begin{tabular}{lllllll}
\hline Author & Ref & Year & Sex & Age at diagnosis & SVT & $\begin{array}{c}\text { Cardiac } \\
\text { rhabdo- } \\
\text { myoma }\end{array}$ \\
\hline Swiderski & 10 & 1962 & M & 2 Years & - & - \\
Martinez & 11 & 1972 & M & 18 Months & + & - \\
Milner & 12 & 1980 & F & 9 Days & - & + \\
Jayaker & 13 & 1986 & M & 2 Weeks & + & + \\
Jayaker & 13 & 1986 & M & 3 Months & + & - \\
Casta & 14 & 1986 & F & Birth & + & + \\
Schneider & 15 & 1986 & M & 9 Months & + & + \\
Yamashita & 16 & 1987 & M & 4 Days & + & + \\
Chitiyat & 17 & 1988 & M & Birth & - & + \\
Manetti & 18 & 1989 & M & 7 Years & $?$ & + \\
Manetti & 18 & 1989 & F & 3 Years & $?$ & + \\
Harding & 19 & 1990 & M & 5 Months & + & + \\
Mehta & 20 & 1993 & F & 36 Hours & + & + \\
Mehta & 20 & 1993 & F & 2 Days & + & + \\
Abushaban & 21 & 1993 & $?$ & ? & + & - \\
Ijaola & 22 & 1994 & F & 24 Years & - & - \\
Nir & 23 & 1995 & $?$ & 6 Months & - & + \\
Nir & 23 & 1995 & $?$ & 6 Months & - & + \\
\hline
\end{tabular}

SVT = supraventricular tachycardia; ? = information not provided in paper.

Table 2 Study cases of Wolff-Parkinson-White (WPW) syndrome and tuberous sclerosis

\begin{tabular}{lllllll}
\hline Case No & Sex & $\begin{array}{l}\text { Age at } \\
\text { diagnosis }\end{array}$ & SVT & $\begin{array}{l}\text { Cardiac } \\
\text { rhabdomyoma }\end{array}$ & $\begin{array}{l}\text { Follow upl } \\
\text { ECG }\end{array}$ & Age at follow up \\
\hline 1 & M & 1 Day & + & + & Normal & 8 Years \\
2 & M & 9 Days & - & + & N/A & Died \\
3 & M & 2 Months & + & + & WPW & 7 Years \\
4 & F & 1 Day & + & + & Normal & 14 Years \\
5 & M & 10 Months & + & + & WPW & 6 Years \\
6 & M & 1 Day & - & + & Normal & 4 Years \\
7 & M & 1 Day & + & + & Normal & 3 Years \\
8 & M & 1 Day & + & + & Normal & 2 Years \\
9 & M & 1 Day & + & + & WPW & 1 Month \\
10 & F & 3.5 Years & + & - & WPW & 3 Years, 10 months \\
\hline
\end{tabular}

SVT = supraventricular tachycardia

Table 3 Localisation of accessory pathways from surface ECG

\begin{tabular}{ll}
$\begin{array}{l}\text { Case } \\
\text { No }\end{array}$ & $\begin{array}{l}\text { Site of accessory } \\
\text { pathway }\end{array}$ \\
\hline 1 & Left lateral \\
3 & Right posteroseptal \\
4 & Right anteroseptal \\
5 & Left posterolateral \\
6 & Left posteroseptal \\
7 & Left posteroseptal \\
8 & Extreme left lateral \\
9 & Left posterolateral \\
10 & Right posterolateral
\end{tabular}

In case No 2 the pathway was not localised, as a full 12-lead ECG was not available. nosed on day 1 , and in all but one the diagnosis was made within the first year of life. A supraventricular tachycardia was the presenting feature in four of the six who were diagnosed on day 1. Eight of the children eventually developed supraventricular tachycardias. All the children were investigated with echocardiograms and nine had evidence of cardiac rhabdomyomata.

Length of follow up ranged from one month to 14 years (median follow up time was four years). One child died aged 30 days from cardiac failure secondary to ventricular outflow obstruction by a cardiac rhabdomyoma. Two children underwent successful cardiac surgery for removal of rhabdomyomata, one for obstruction of the tricuspid valve and the other for obstruction of the left ventricular outflow tract. Follow up ECGs were obtained from the nine survivors and showed resolution of the Wolff-Parkinson-White syndrome in five. The accessory pathway was localised in nine children (table 3): six had a pathway on the left side of the heart and three on the right. We were unable to localise the pathway in patient No 2 because a full 12-lead ECG was not available.

\section{Discussion}

This is the largest collection of tuberous sclerosis patients with Wolff-Parkinson-White syndrome published to date. The prevalence of this syndrome in tuberous sclerosis is unknown and cannot be determined from our study. A recent review of tuberous sclerosis and cardiac rhabdomyomata suggested that $9-13 \%$ of patients with rhabdomyomata have the WolffParkinson-White syndrome, but this was in a selected hospital based population. ${ }^{23}$ In a study conducted in the south of England in 1996, 131 cases of tuberous sclerosis were identified, among whom there were two with symptomatic Wolff-Parkinson-White syndrome who were alive on the census date ${ }^{8}$; this suggests a possible prevalence of $1.5 \%$ in tuberous sclerosis, compared with $0.15 \%$ (both symptomatic and asymptomatic) in the general population. ${ }^{24}$

We found evidence of sex bias in cases of Wolff-Parkinson-White syndrome and tuberous sclerosis (eight males, two females), and there seems to be a similar male bias in cases of rhabdomyomata and tuberous sclerosis-in Nir's study of cardiac rhabdomyomata and tuberous sclerosis from the Mayo clinic, $60 \%$ of cases were male. ${ }^{23}$ Wolff-Parkinson-White syndrome in the general population also appears to be more common in males than in females: Sherf and Neufeld reviewed 23 series from the literature and found that $65 \%$ of the cases occurred in males. ${ }^{27}$

The aetiology of Wolff-Parkinson-White syndrome in tuberous sclerosis has not been explained. It has been known for some time that some of the cells in the cardiac rhabdomyomata found in patients with tuberous sclerosis are structurally identical to normal Purkinje cells, so it has been presumed that rhabdomyomatous tissue traversing the atrioventricular junction acts as the accessory pathway bypassing the atrioventricular node. ${ }^{28}$ This theory is compatible with the results of our survey. All but one of our patients had echocardiographic evidence of cardiac rhabdomyomata. There are four published cases of Wolff-Parkinson-White syndrome occurring in tuberous sclerosis apparently without cardiac rhabdomyomata, but two of these cases were reported before echocardiography became a routine investigation, so a rhabdomyoma could have been missed. ${ }^{10}{ }^{11}$ In a third case, aged 3 months at diagnosis, and in case number 10 in our series, who was 3.5 years old at diagnosis, it is possible that rhabdomyomatous tissue could already have regressed by the time of echocardiography, as we have seen large rhabdomyomata completely disappear on echocardiogram within a period of six weeks from birth. ${ }^{13}$ It is also likely that some cardiac rhabdomyomata may be too small to be seen on echocardiography.

Our cases show a high resolution rate on at least one follow up ECG (five of nine survivors), compared with Wolff-ParkinsonWhite syndrome in the general population. Resolution of Wolff-Parkinson-White syndrome over time is well documented: in a longitudinal study of 42 children by Swiderski et al, six resolved. ${ }^{10}$ Gillette et al report that $29 \%$ of their sample of 98 patients with WolffParkinson-White syndrome had no evidence of pre-excitation on multiple follow up ECGs, ${ }^{24}$ while Perry et al found that $26 \%$ of their series of 140 patients lost their pre-excitation pattern. ${ }^{29}$ The higher rate of resolution of Wolff-Parkinson-White syndrome in tuberous 
sclerosis patients could be explained by the fact that rhabdomyomata are known to regress over time and therefore the accessory pathway may disappear or cease to conduct. However, there is at least one reported case of WolffParkinson-White syndrome in an adult with tuberous sclerosis. ${ }^{22}$

Our study highlights the association between tuberous sclerosis and supraventricular tachycardia, with overt pre-excitation visible on the ECG. Tuberous sclerosis may also be associated with supraventricular tachycardias in the absence of overt pre-excitation, though probably less often. In researching this paper we discovered one additional tuberous sclerosis patient with a supraventricular tachycardia and a short PR interval on ECG but no evidence of a delta wave. This patient presented on day 1 of life and did have cardiac rhabdomyomata. It is likely that the underlying mechanism for his arrhythmia was the same as in the patients with tuberous sclerosis and Wolff-Parkinson-White syndrome, but that his accessory pathway was concealed.

The hypothesis that Wolff-Parkinson-White syndrome in tuberous sclerosis may be caused by something which is present early in life but which later resolves is supported by the fact that all but one of our cases presented within the first year of life and six of 10 presented on day 1. Eight of 10 patients developed symptomatic arrhythmias, all supraventricular tachycardias. Symptomatic cases responded well to conventional drug treatment chosen by their local physician. Wolff-Parkinson-White syndrome in this group of tuberous sclerosis patients was not life threatening and resolved over time in the majority. However, serious complications are possible, both in utero and in infancy.

The association of cardiac rhabdomyomata and fetal hydrops has been described. ${ }^{30}$ There are two possible mechanisms. First, rhabdomyomata may cause severe obstruction within the heart, leading to cardiac failure. Second, rhabdomyomata may provoke fetal arrhythmias which in turn lead to cardiac failure. Several different types of arrhythmia have been described in the fetus in combination with cardiac rhabdomyomata (with or without tuberous sclerosis), and two of these cases had fetal supraventricular tachycardias. ${ }^{31} 32$ Neither was proven to have tuberous sclerosis but there is no reason to doubt that a fetus with tuberous sclerosis could develop an atrioventricular reentry tachycardia related to Wolff-ParkinsonWhite syndrome, leading to heart failure and hydrops.

Sudden unexpected death in infancy has been documented in tuberous sclerosis. This has been attributed to a cardiac cause, following exclusion of neurological causes and because multiple rhabdomyomata were found at necropsy, but no precise cardiac mechanism has been elucidated. ${ }^{23} \mathrm{It}$ is possible that some of these fatalities may be caused by atrial arrhythmias which, when associated with anterograde conduction down an accessory pathway, provoke ventricular fibrillation. A child with tuberous sclerosis and cardiac rhabdomyomata has been reported with clinical progression from supraventricular tachycardia to ventricular fibrillation to death, which could be explained by this mechanism. ${ }^{16}$ Case et al have reported on a 9 month old child with multiple rhabdomyomata presenting with complex supraventricular and ventricular arrhythmias who was resistant to medical treatment and subsequently died of congestive heart failure. ${ }^{33}$ These complications are clearly rare.

In conclusion, we have highlighted the association between Wolff-Parkinson-White syndrome and tuberous sclerosis. This occurs more often in males and almost exclusively in association with cardiac rhabdomyomata. It presents early in life, often on day 1 , and is usually associated with symptomatic supraventricular tachycardia. It responds well to medical treatment and a high proportion of cases will resolve over time. In this series the complication did not cause serious morbidity, but in rare instances serious complications could occur. Infants diagnosed with tuberous sclerosis should always have an ECG to exclude the possibility of pre-excitation.

We thank Dr Nick Archer, consultant paediatric cardiologist, John Radcliffe Hospital, Oxford; Dr Elliot Shinebourne, consultant paediatric cardiologist, Royal Brompton National Heart and Lung Hospital; and Dr Neil Aiton, lecturer in neonatology, St Michael's Hospital, Bristol, for their help in finding patients for this study. We are also grateful to Dr J Morgan, consultant cardiologist and electrophysiologist, Southampton General Hospital, for his help in identifying the site of the accessory pathways from the surface ECGs. FJKO'C is currently supported by a Wellcome Trust Training Fellowship and has previously been supported by a grant from the Tuberous Sclerosis Association of Great Britain. ACC was supported by a grant from the Wessex Regional Health Authority. We also acknowledge the support of the Bath Unit for Research into Paediatrics.

1 Fryer AE, Chalmers A, Connor JM, et al. Evidence that the gene for tuberous sclerosis is on chromosome 9. Lancet 1987;i: $659-61$.

2 Kandt RS, Haines JL, Smith M, et al. Linkage of an important gene locus for tuberous sclerosis to a chromosome 16 marker for polycystic kidney disease. Nature Genet 1992;2: 37-41.

3 The European Chromosome 16 Tuberous Sclerosis Consortium. Identification and characteristics of the tuberous sortium. Identification and characteristics of the tuberous

4 van Slegtenhorst M, de Hoogt R, Hermans C, et al. Identifivan Slegtenhorst $M$, de Hoogt R, Hermans C, et al. Identifi-
cation of the tuberous sclerosis gene TSC 1 on chromocation of the tuberous sclerosis gene
some 9q34. Science 1997;277:805-8.

some 9q34. Science 1997;277:805-8.
5 Green AJ, Johnson P, Yates JRW. The tuberous sclerosis gene on chromosome $9 \mathrm{q} 34$ acts as a growth suppressor. Hum Mol Genet 1994;3:1833-4.

6 Vogt H. Zur diagnostik der Tuberosen Sklerose. $Z$ Erforsch Behandl fugendl Schwachsinns 1908;2:1-12.

7 Osborne JP, Fryer AE, Webb DR. Epidemiology of tuberous sclerosis. Ann N Y Acad Sci 1991;615:125-7.

8 Webb DR, Fryer AE, Osborne JP. Morbidity associated with tuberous sclerosis: a population study. Dev Med Child Neurol 1996; 38:146-55

9 Webb DR, Thomas RD, Osborne JP. Cardiac rhabdomyomas and their association with tuberous sclerosis. Arch Dis
Child 1993; 68:367-70.

10 Swiderski J, Lees MH, Nodas AS. Wolff-Parkinson-White syndrome in infancy and childhood. Br Heart $\mathcal{f} 1962 ; 24$ : $561-9$.

11 Martinez J, Bardier A, Pasternac A. Spasmes en flexion et troubles du rythme cardiaque, étiologie discutée, toxoplasmose ou sclérose tubéreuse de Bourneville. Arch Fr Pediatr 1972;29:434

12 Milner S, Abramowitz JA, Levin SE. Rhabdomyoma of the heart in a newborn infant. Diagnosis by echocardiography. Br Heart f 1980;44:224-7.

13 Jayaker PB, Stanwick RS, Seshia SS. Tuberous sclerosis and Wolff-Parkinson-White syndrome. $\mathcal{F}$ Pediatr 1986;108:25960.

14 Casta A. Tuberous sclerosis and Wolff-Parkinson-White syndrome [letter]. F Pediatr 1986;109:399-400.

15 Schneider A, Tschirky B, Arbenz U, et al. Cardiac rhabdomyoma in familial tuberous sclerosis. Helvetica Paediatrica Acta 1986;41:77-85.

16 Yamashita $\mathrm{H}$, Nagaoka $\mathrm{H}$, Matsushima $\mathrm{R}$, et al. Cardiac rhabdomyoma associated with tuberous sclerosis. An autopsy case of a newborn infant who died of cardiac failautopsy case of a newborn infant who
ure. Acta Pathol fpn 1987;37:645-53. 
17 Chitiyat D, McGillivray BC, Diamant S, et al. Role of pre-natal detection of cardiac tumours in the diagnosis of tuberous $\mathrm{s}$

18 Manetti A, De Simone L, Favilli S, et al. Echocardiographic study of heart rhabdomyoma in tuberous sclerosis. Giornale Italiano di Cardiologia 1989;19:319-23.

19 Harding CO, Pagon RA. Incidence of tuberous sclerosis in patients with cardiac rhabdomyoma. Am $\mathcal{f}$ Med Genet 1990;37:443-6.

20 Mehta AV. Rhabdomyoma and ventricular preexcitation syndrome. A report of two cases and review of literature. Am ₹ Dis Child 1993;147:669-71.

21 Abushaban L, Denham B, Duff D. Ten year review of cardiac tumours in childhood. Br Heart f 1993;70:166-9.

22 Ijaola O, Festus-Abibo LC, Lawani O, et al. Cardiac involvement (Wolff-Parkinson-White syndrome) in tuberous sclerosis. Postgrad Med f 1994;70:124-7.

23 Nir A, Tajik J, Freeman WK, et al. Tuberous sclerosis and cardiac rhabdomyoma. Am f Cardiol 1995;76:419-21.

24 Gillette PC, Blair HL, Crawford FA. Preexcitation syndromes. In: Gillette PC, Garson A, eds. Pediatric cardiac dromes. In: Gillette PC, Garson A, eds. Pediatric cardiac 79 .

25 Gomez MR. Criteria for diagnosis. In: Gomez MR, ed. Tuberous sclerosis, 2nd Ed. New York: Raven Press, 1988:920.
26 Fitzpatrick AP, Gonzales RP, Lesh MD, et al. New algorithm for the localization of accessory atrioventricular connections using a baseline electrocardiogram. $\mathcal{f} \mathrm{Am}$ Coll Cardiol 1994;23:107-16.

27 Scherf L, Neufeld HN. Prognosis. In: The pre-excitation syndrome: facts and theories. New York: Yorke Medical Books, 1978:162-78.

28 Crome L. The structural features of epiloia, with special refrence to endocardial fibroelastosis. F Clin Pathol 1954;7: 137.

29 Perry JC, Garson A. Supraventricular tachycardia due to Wolff-Parkinson-White syndrome in children: early disappearance and late recurrence. F Am Coll Cardiol 1990;16: $1215-20$.

30 Calhoun BC, Watson PT, Hegge F. Ultrasound diagnosis of an obstructive cardiac rhabdomyoma with severe hydrops and hypoplastic lungs. A case report. f Reprod Med 1991;36:317-9.

31 Geva T, Sandni F, Pear W, et al. Cardiac rhabdomyoma. Rare cause of fetal death. Chest 1991;99:139-42.

32 Kim CJ, Cho JH, Chi JG, et al. Multiple rhabdomyoma of the heart presenting with a congenital supraventricular tachycardia-report of a case with ultrastructural study. $\mathcal{F}$

33 Case CL, Gillette PC, Crawford FA. Cardiac rhabdomyoma causing supraventricular and lethal ventricular arrhythmia in an infant. Am Heart $\mathcal{F} 1991 ; 122: 1484-6$. 